Space physics

\title{
NASA told to be be more active
}

Washington

THE US National Research Council has told the National Aeronautics and Space Administration (NASA) to reverse the "long-term decline" in Solar System space physics, and has helpfully prescribed an ambitious series of projects to accomplish the task. The council's report* on the subject urges NASA to give highest priority to the International Solar Terrestrial Physics programme (ISTP), for which launches should start in 1989.

This influential support for ISTP should be music to the ears of NASA's partners in the project, Japan and the European Space Agency (ESA); three years ago, NASA infuriated European scientists by reneging on a promise to supply a satellite for the International Solar Polar Mission (now known as Ulysses). NASA officials now say there is "a reasonably good chance" that the agency will include funds to start work on ISTP in its budget request for fiscal year 1987 which NASA will finalize by 15 September.

The other two missions vying with ISTP for inclusion as a 1987 "new start" are
TOPEX (a satellite to measure ocean topography) and CRAF (Comet Rendezvous and Asteroid Flyby); the latest betting at NASA headquarters is that TOPEX and either CRAF or ISTP will be approved. In addition, the 1987 budget request is likely to include work on the mirror for AXAF, the Advanced X-Ray Astronomy Facility. By developing AXAF in stages, NASA hopes to avoid the embarrassing cost over-runs that plagued development of the Hubble Space Telescope.

The National Research Council Report, chaired by Stamatios M. Krimigis of the Applied Physics Laboratory at Johns Hopkins University, assumed a plausible (if hopeful) budget for Solar System space science of $\$ 400$ million by 1987 (in 1985 dollars); the current figure is $\$ 300$ million. NASA officials say the projects described in Krimigis's report are well justified and that it will be for Congress to decide how many will be funded.

Krimigis's report gives its blessing to the Upper Atmosphere Research Satellite, now being developed, and urges "immedi-

\section{European research}

\section{EEC plans risk management}

Brussels

THE European Commission has suggested to ministers of the European Economic Community (EEC) that 15 million ECU (European Currency Units, $1 \mathrm{ECU}=$ $£ 0.60$ ) be provided over the next five years for research into the prevention, prediction and management of industrial accidents involving chemicals such as those that occurred in Seveso, Italy, in 1976 and last December in Bhopal, India.

Part of the new five-year 150 million ECU programme that also includes environmental protection and climatology, contracts on major technical hazards, to which the Community would contribute half the costs, will complement research already under way at the commission's own Joint Research Centre. These contracts will involve both industry and research institutes. It is hoped also to involve researchers from outside the EEC.

The aim will be to improve the scientific foundation of risk analysis by studying the physical and chemical phenomena of dispersion, runaway reactions and other causes of chemical accidents. There will also be an attempt to improve or replace hazardous processes, to improve safety technology, and to detect and mitigate high-risk situations. The Commission proposes that a start should be made on the transportation of bulk hazardous substances and on hazardous production processes.

The proposal would strengthen EFC legislation sparked off by the Seveso disaster, when highly toxic dioxin was spewed accidentally over a north Italian town. The directive on the prevention of major industrial accidents came into force in 1981 , but its implementation has posed difficulties for the member states.

In the environmental part of the research programme, for which 65 million ECU has been set aside, emphasis will be placed on health and ecological effects of pollution (particularly the deterioration of historic monuments), air, water and soil quality (including the impact of farming practices), waste, chemicals assessment (including the development of methods to avoid using vertebrates in toxicity tests) and noise. Emphasis will be put on advanced pollution abatement technology, in the hope that the outcome will also improve industrial competitiveness and employment prospects.

The Commission also intends to promote training in environmental sciences. Finally, 250 million ECU will be set aside for the second phase of a programme of long-term climate research. Work will continue on the physical basis of climate modelling, seasonal forecasting of European climates, climate sensitivity, effects of changes in atmospheric composition (via carbon dioxide and trace gases) and changes in land-surface properties, detection of climatic change and climatic impact on land, water, vegetation and marine resources.
Anna Lubinska ate" funding for development of the Solar Optical Telescope, a 1.25-metre-aperture instrument that would form the basis of a solar observatory on the space station. It also wants to see a start on a long talkedabout solar probe that would approach the Sun to within 4 solar radii; work should begin immediately on a heat shield for the mission in time for a possible launch in 1995. Looking further to the future, the committee gives its blessing to a solar polar orbiter that could be launched by the end of the century if a suitable propulsion system is developed.

Besides the highly visible major missions, the research council endorses an expansion of ground-based modelling and theoretical work in plasma physics; one goal is to provide an account of how disturbances on the Sun affect the heliosphere and thence the magnetospheres, ionospheres and upper atmospheres of the Earth and planets. There should also be a series of Explorer payloads, according to the committee, starting in the $1990 \mathrm{~s}$, to investigate Solar System space physics.

Besides being extremely colourful, the report is admirably specific in its recommendations. The committee's purpose might well be to avoid the fate of the 1980 Kennel Report on the same subject, on which the committee plaintively notes there has been "no significant progress" because of budget constraints.

Tim Beardsley ${ }^{*}$ An implementation plan for priorities in Solar-System space physics (Executive summary). Committee on Solar and Space Physics, National Research Council, 1985.

\section{Polish protest (cont'd)}

Poland's unofficial Social Committee for Learning, SKN (Nature 314, 123; 1985) has been quick to respond to the enactment, on 25 July, of the government-sponsored amendments to the 1982 Higher Education Act. A copy of SKN's irregular news bulletin Servis informacyjny $S K N$, dated 28 July, presents a reprint of the official announcement of the new law with the "tentative summary" of the effect of the changes, prepared by the Main Council for Science and Technology, the official representative body of the universities.

In the opinion of the Main Council, "without embarking on a major discussion of the motives and grounds for the proposed changes, they are clearly aimed at the creation of a legal framework for the direct and centralized direction of all matters relating to higher education in Poland, not only in questions of its organization but also in a wide range of questions of cadre policy and scientific research, not excluding legalized para-censorship".

The SKN bulletin also notes, however, that in the opinion of Deputy Jarema Maciszewski, who presented the bill to the Sejm: "The proposed changes do not contravene the idea of university selfgovernment, but simply restore its purely academic character".

Vera Rich 